\title{
SISTEM PERINGATAN DINI BENCANA BANJIR BERBASIS MIKROKONTROLER ARDUINO
}

\author{
Fadlul Rahman Usman ${ }^{1 *}$, Wrastawa Ridwan ${ }^{2}$, Iskandar Zulkarnain Nasibu ${ }^{3}$ \\ ${ }^{123}$ Prodi Teknik Elektro, Fakultas Teknik, Universitas Negeri Gorontalo \\ Jl. Jend. Sudirman No.6 Kota Gorontalo 96128 Indonesia \\ Email: *fadlulrahmanusman@yahoo.co.id ${ }^{1}$, wridwan@ung.ac.id, zul.nasibu@ung.ac.id
}

\begin{abstract}
Abstrak
Banjir hingga saat ini menjadi maslah serius di berbagai daerah indonesia, dibeberapa daerah mempunyai tekstur tanah yang buruk yang tidak mempunyai daya serapan air yang baik, atau jumlah curah hujan yang melebihi kemampuan tanah untuk menyerap air, ketika hujan turun yang kadang terjadi adalah banjir yang datang secara tiba-tiba diakibatkan terisinya saluran air kering dengan air. Agar dapat memberikan peringatan akan adanya bencana banjir diperlukan suatu sistem peringatan dini, menggunakan SMS gateway dan web server.Pada penelitian ini, sistem menggunakan web browser dan SMS gateway sebagai media pengirim informasi ketinggian air kepada petugas monitoring. Sistem ini menggunakan mikrokontroler Arduino Uno Atmega328 untuk pembacaan sensor air, menampilkan data di LCD, menghidupkan led dan mengirim data ketinggian air melalui web browser dan SMS. Berdasarkan hasil perancangan sistem yang telah dilakukan pada sistem peringatan dini bencana banjir berbasis mikrokontroler Arduino yang diimplementasikan dalam bentuk prototype telah bekerja dengan baik sesuai dengan perancangan yang direncanakan.
\end{abstract}

Kata Kunci : Banjir, peringatan dini, SMS, ethernet shield, arduino

\begin{abstract}
Flooding to date has become a serious problem in many parts of Indonesia, in some areas have poor soil texture that does not have good air absorption, or the amount of rainfall that exceeds the ability of the soil to absorb the air, the amount of rain that falls is the coming flood suddenly caused by dry air ducts with air. In order to provide an explanation of the existence of flood disaster in accordance with the information system early, using SMS gateway and web server. In the design stage of this final task, the system uses a web browser and SMS gateway as a medium of sending air altitude information to monitoring officers. The system uses Arduino Uno Atmega328 microcontroller for air sensor readings, displays data in LCD, led drive and sends air altitude data via web browser and SMS. Based on the results of the formulation of systems that have been done on information systems used in the form of prototype has worked well in accordance with the proven design.
\end{abstract}

Keywords : Flood, early warning, SMS, ethernet shield, arduino

\section{PENDAHULUAN}

Berdasarkan Undang-Undang nomor 24 tahun 2007, pengertian bencana adalah peristiwa atau rangkaian peristiwa yang mengancam dan mengganggu kehidupan dan penghidupan masyarakat yang disebabkan, baik faktor alam dan faktor non alam maupun faktor manusia, sehingga mengakibatkan timbulnya korban jiwa manusia, kerusakan lingkungan, kerugian harta benda dan dampak psikologis. Sedangkan Bencana alam adalah bencana yang diakibatkan oleh peristiwa atau serangkaian yang disebabkan oleh alam antara lain berupa gempa bumi, tsunami, gunung meletus, kekeringan, angin topan, tanah longsor dan banjir.

Salah satu bencana alam yang sering terjadi di beberapa daerah yaitu bencana banjir yang dapat berupa genangan air pada lahan yang biasanya kering seperti lahan pertanian, pemukiman dan pusat kota. Banjir dapat juga terjadi karena debit atau volume air yang mengalir pada suatu sungai atau saluran drainase melebihi atau diatas kapasitas pengalirannya (Rosyidie, 2013).

Dibeberapa daerah di gorontalo mempunyai tekstur tanah yang buruk yang tidak mempunyai daya serapan air yang baik, atau jumlah curah 
hujan yang melebihi kemampuan tanah untuk menyerap air ketika hujan turun yang kadang terjadi adalah banjir yang datang secara tiba-tiba diakibatkan terisinya saluran air kering dengan air. Pada tahun 2017 terjadi bencana banjir yang mengakibatkan kerugian yang tidak sedikit dikalangan masyarakat Limboto kabupaten Gorontalo, ini kurangnya persiapan masyarakat untuk mengantisipasi datangnya bahaya banjir. Masyarakat juga harus mulai tanggap terhadap bencana alam yang bisa terjadi kapan saja. Salah satu bentuk ketanggapan terhadap bencana banjir yang dapat dilakukan yaitu mengenai informasi peringatan dini.

Agar dapat memberikan peringatan dini akan adanya bencana banjir, diperlukan suatu sistem yang dapat mendeteksi terjadinya perubahan ketinggian air sungai, salah satunya adalah dengan menggunakan sensor, kemampuan dasar dari sensor adalah untuk mendeteksi adanya perubahan lingkungan fisik maupun kimia. Sensor itulah yang akan mendeteksi perubahan ketinggian air sungai, jika air telah melampaui batas level yang telah ditentukan maka akan secara otomatis memberikan peringatan banjir melalui SMS gateway dan web browser yang terhubung secara point to point ke petugas monitoring sungai yang selanjutnya dapat diinformasikan kepada masyarakat. Dengan peringatan tersebut masyarakat dapat mempersiapkan diri, agar kerugian dapat ditekan seminim mungkin. Hal inilah yang melatar belakangi penulis untuk membuat sistem peringatan dini bencana banjir

\section{BAHAN DAN METODE}

\section{Arduino Uno}

Arduino Uno merupakan sebuah mikrokontroler yang berbasis open source, yaitu mikrokontroler yang dapat dikembangkan oleh pihak ketiga yang memudahkan pengguna dalam mengembangkan proyek-proyek automasi dan mikrokontroler lainnya dengan mudah.

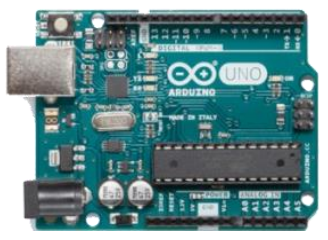

Gambar 1 Board Arduino
Pada gambar 1 merupakan board Arduino. Peranti ini dapat dimanfaatkan sebagai rangkaian elektronik dari yang sederhana hingga yang sangat kompleks, bahkan dengan menambahkan beberapa komponen tertentu peranti ini dapat dipakai untuk pemantauan jarak jauh melalui internet, seperti smart home (Kadir,2012).

\section{SMSGateway}

SMS gateway adalah sebuah perangkat lunak yang menggunakan bantuan komputer dan memanfaatkan teknologi seluler yang diintegrasikan guna mendistribusikan pesan-pesan yang dipadukan lewat sistem informasi melalui media SMS yang ditangani oleh jaringan seluler. Pada Gambar 2 merupakan alur kerja SMS. SMS Gateway biasanya support untuk pesan yang berupa teks, unicode character, dan juga smart messaging ringtone, picture message, logo operator dan lain-lain (Afrina,2015).

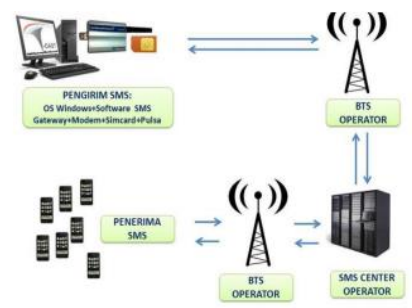

Gambar 2 Alur kerja SMS

\section{Sim 900 Gsm/Gprs}

Modul SIM900 GSM/GPRS adalah bagian yang berfungsi untuk berkomunikasi antara pemantau utama dengan handphone. Modul ini dapat berkomunikasi dengan mikrokontroler melalui komunikasi serial,. Komunikasi melalui SMS ini difungsikan untuk mengirimkan kondisi ketinggian permukaan air. Pada gambar 3 merupakan board GSM Shield Sim 900

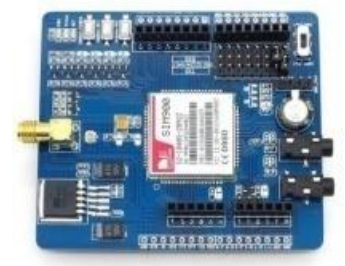

Gambar 3 Gsm Shield Sim 900 


\section{Jaringan Komputer}

Jaringan komputer adalah seperangkat alat komunikasi yang saling terhubung antara yang satu dengan yang lainnya dengan tujuan untuk bisa bertukar data informasi. Konsep awal berkembangnya jaringan komputer adalah komunikasi data dari satu komputer ke komputer lainnya. Komunikasi data tersebut bersifat pointto-point, jadi hanya ada dua komputer yang akan terhubung (Ikhsan,2014).

Metode Penelitian :Metode penelitian yang digunakan dalam penelitian tugas akhir ini adalah sebagai berikut :

\section{Studi Pustaka}

Studi pustaka dilakukan dengan mencari informasi tentang penelitian baik berupa buku, jurnal, internet, dan juga dari sumber lainnya yang mendukung perancangan sistem alat berdasarkan landasan teori yang seperti di jelaskan pada Bab II.

\section{Eksperimen}

Melakukan pembuatan alat dan percobaan sistem serta melakukan pengujian sensor agar alat dapat berfungsi dengan normal.

\section{Diagram Blok}

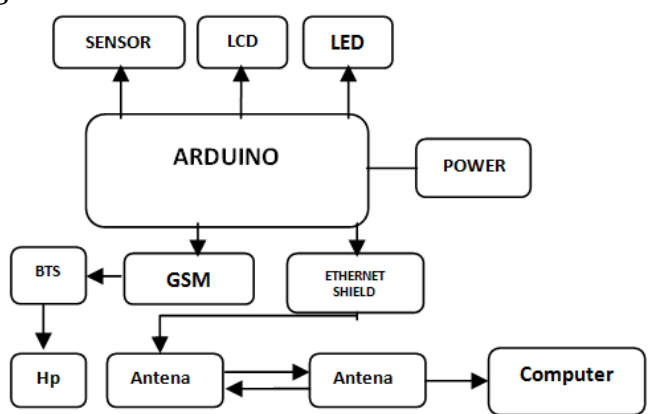

Gambar 4 Blok Digram Rangkaian

Rangkaian Sensor Air : Penempatan sensor air yaitu ditempelkan pada sisi pipa dengan jarak 15 centimeter. sensor yang digunakan dalam perancangan alat ini menggunakan sistem ADC (analog digital converter) yang ada di Arduino, dimana ADC ini berfungsi sebagai pengubah data analog menjadi data digital dengan nilai pembacaan dari 0 sampai 1023. Data yang akan diproses menggunakan sebuah sinyal processing, akan tetapi pemrosesan kurang efektif dikarenakan akurasi pembacaan relatif kecil maka data analog tersebut harus di ubah ke dalam bentuk digital dengan menggunakan Analog Digital Converter (ADC).

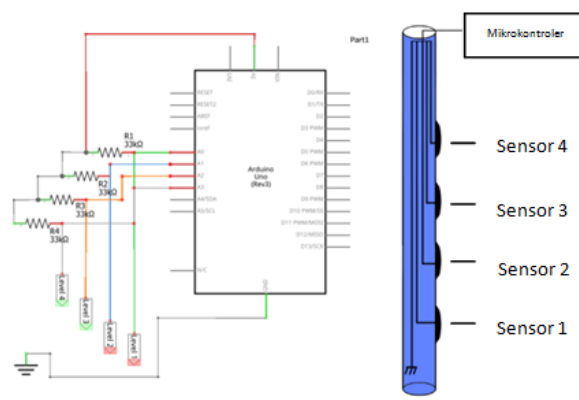

Gambar 5 Rangkaian ADC sebagai sensor

Untuk dapat mengubah data analog menjadi data digital dibutuhkan rumus konversi nilai analog menjadi nilai digital, rumus dari konversi ADC dengan resolusi 10 bit sebagai berikut:

$\mathrm{ADC}=\frac{V \text { in } \times 1024}{V \text { ref }} \quad$ persamaan $(3.1)$

Keterangan :

$$
\begin{array}{ll}
\mathrm{V}_{\text {in }} & =\text { Input sinyal } \mathrm{ADC}=1024 \\
\mathrm{ADC} & =\text { Nilai } \mathrm{ADC} \\
\text { Vref } & =\text { Tegangan sumber }
\end{array}
$$

Karena menggunakan rangkaian sensor air dengan menggunakan sistem ADC maka diperlukan sebuah rangkaian pembagi tegangan, Pembagi tegangan merupakan rangkaian atentuator yang berfungsi untuk memperkecil tegangan atau sinyal, Rangkaian pembagi tegangan memerlukan sumber tegangan yang disambungkan secara seri dengan dua resistor, rangkaian pembagi tegangan

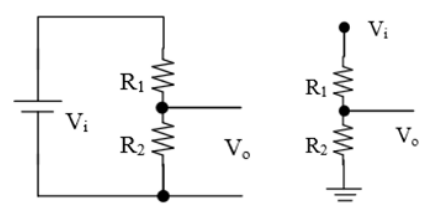

dapat dituliskan rumus pembagi tegangan seperti pada persamaan 1

$\mathrm{V}_{\text {out }}=\frac{V \text { in }}{R} \times \mathrm{R}_{2}$ Persamaan

Maka perhitungan untuk mengetahui nilai

Vin dari rangkaian sensor sebagai berikut:

Diketahu :

$$
\begin{aligned}
& \mathrm{R} 1=33 \mathrm{~K} \Omega \\
& \mathrm{R}_{2}=15 \mathrm{~K} \Omega \text { (nilai tahanan air yang }
\end{aligned}
$$
telah diukur)

$$
\mathrm{V}_{\text {in }} \quad=5 \text { volt (tegangan Arduino) }
$$




$$
\mathrm{V}_{\text {out }} \quad=\ldots ?
$$

Penyelesaian :

$$
\begin{aligned}
\mathrm{V}_{\text {out }} & =\mathrm{Vr}_{2} \\
\mathrm{~V}_{\text {out }} & =\mathrm{Ir}_{2} \times \mathrm{R}_{2}
\end{aligned}
$$

Maka diturunkan

$$
\begin{aligned}
\mathrm{V}_{\text {out }} & =\frac{V \text { in }}{R} \times \mathrm{R}_{2} \\
\mathrm{~V}_{\text {out }} & =\frac{V \text { in }}{R 1+R 2} \times \mathrm{R}_{2} \\
\mathrm{~V}_{\text {out }} & =\frac{5 \text { Volt }}{33 K \Omega+15 K \Omega} \times 15 \mathrm{~K} \Omega
\end{aligned}
$$

Maka Diperoleh :

$$
\mathrm{V}_{\text {out }} \quad=\frac{75000}{48000 \Omega}=1,5625 \text { Volt }
$$

Hasil dari perhitungan pengukuran diatas diperoleh nilai analog yaitu sebesar $1,5625 \mathrm{~V}$, sehingga hasil tersebut akan di ubah kedalam bentuk digital menggunakan rumus konversi ADC sebagai berikut:

Diketahui :

$$
\begin{aligned}
\mathrm{V}_{\text {in }} & =1,5625 \text { Volt } \\
\text { Vref } & =5 \text { Volt } \\
\mathrm{ADC} & =\ldots ?
\end{aligned}
$$

Penyelesaian :

$$
\mathrm{ADC}=\frac{V \text { in } x 10 \text { bit }}{V r e f}
$$

Maka :

$$
\mathrm{ADC}=\frac{1,5625 \text { Voltx } 1024}{5 \text { Volt }}
$$

Maka Diperoleh : $\mathrm{ADC}=320$

Dari hasil perhitungan menggunakan rumus konversi ADC yang merubah nilai analog menjadi nilai digital diperoleh sebesar 320 yang merupakan nilai aktif dari sensor sehingga mikrokontroler akan memproses sebagai perintah bahwa sensor aktif. Yang selanjutnya akan memproses keseluruhan sistem ini.

\section{HASIL DAN PEMBAHASAN}

\section{Hasil Prototype system}

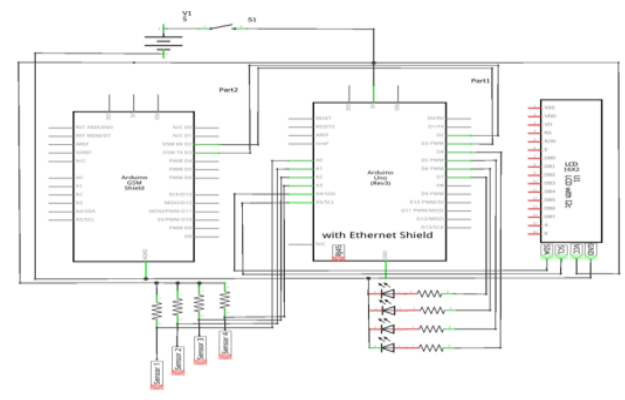

Gambar 6 Skema rangkaian prototype sistem
Dari skema rangkaian gambar 9 dijelaskan prinsip kerja alat ini yaitu :mikrokontroler diberi suply tegangan menggunakan adaptor 9v. Karena sistem ini menggunakan ethernet shield maka shield dipasang langsung ke Arduino, selanjutnya pin A1, A2, A3 dan A4 dihubungkan langsung dengan sensor air 1, 2, 3 dan 4, sedangkan untuk pin D4, D5, D6 dan D7 terhubung dengan resistor yang mengarah ke LED 1, 2, 3, 4, akan menyala salah satu led apabila air menyentuh salah satu tangkai sensor. untuk pin D2 dan D3 di mikrokontroler terhubung langsung dengan $\mathrm{Rx}$, Tx dari Gsm shield Untuk pin A4 dan A5 terhubung dengan I2c pin scl dan pin sda pada LCD dan untuk grounding dari sensor, LCD, LED, Gsm shield terhubung secara keseluruhan.

Hasil Pengujian Rangkaian Keseluruhan Alat : Setelah melalukan pengujian dari komponen pada masing-masing alat, selanjutnya melakukan pengujian alat secara keseluruhan berupa input, proses dan output yang digabungkan secara keseluruhan.Tampilan web browser sistem peringatan dini bencana banjir saat sensor tidak menyentuh air.

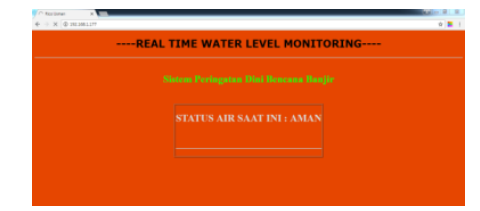

Gambar 7 Tampilan Web Browser saat sensor tidak menyentuh air

Saat sensor level 1 dihubungkan dengan air maka kondisi air dalam keaadaan siaga 1 sehingga output pada web browser menampilkan status air siaga 1 dan handphone menerima notifikasi SMS bahwa status level air siaga 1 serta LCD menampilkan status ketinggian air. 


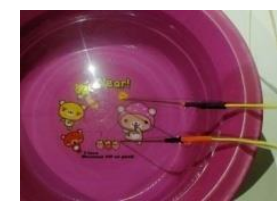

(a)

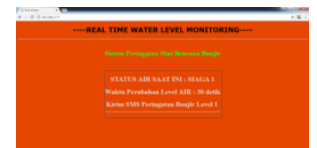

( c )

Gambar 8 (a) Sensor Level 1 dihubungkan air (b) Notifikasi SMS masuk (c) Tampilan web browser

Berbeda saat sensor level 2, 3 dan 4 dihubungkan dengan air, maka akan ada tampilan status air saat ini dan laju perubahan tinggi air dengan kecepatan detik pada web browser serta notifikasi SMS yang berbeda berikut merupakan tampilan alat, notifikasi SMS dan web saat sensor level 2 dihubungkan dengan air maka kondisi air dalam keadaan siaga 2, dan pada handphone menerima notifikasi SMS bahwa status level air siaga 2 dan web browser menampilkan status air saat ini siaga 2 dan laju perubahan tinggi air.

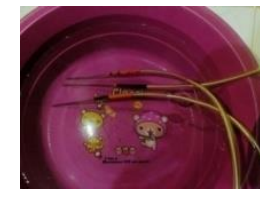

(a)

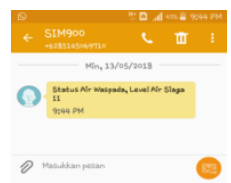

(b)

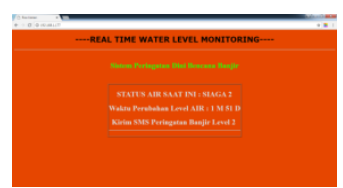

(c)

Gambar 9 (a) sensor level 2 dihubungkan air (b) notifikasi SMS saat air level 2 (c) tampilan web browser saat level 2

Selanjutnya tampilan alat, notifikasi SMS dan web browser saat sensor level 3 dihubungkan dengan air maka kondisi air dalam keadaan siaga 3, sehingga output pada handphone menerima notifikasi SMS bahwa status level air siaga 3 dan web browser menampilkan status air saat ini siaga 3 dan laju perubahan tinggi air.

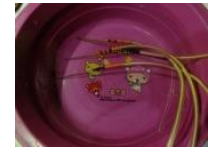

(a)

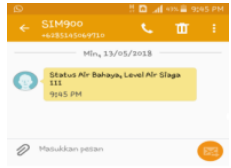

(b)

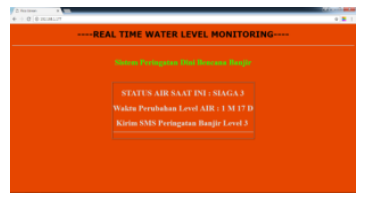

(c)

Gambar 10 (a) Sensor level 3 dihubungkan dengan air (b) Notifikasi SMS saat air level 3 (c) Tampilan web browser saat level 3

Selanjutnya tampilan alat, notifikasi SMS dan web saat sensor level 4 dihubungkan dengan air maka kondisi air dalam keadaan siaga 4, sehingga output pada handphone menerima notifikasi SMS bahwa status level air siaga 4 dan web browser menampilkan status air saat ini siaga 4 dan laju perubahan tinggi air, seperti pada Gambar 11. Sistem peringatan dini bencana banjir ini hanya menggunakan 4 level ketinggian air, dan akan terus berulang cara kerja dari sistem ini yaitu mikrokontroler akan mengaktifkan keseluruhan sistem jika ada salah satu atau lebih tangkai sensor yang menyentuh air.

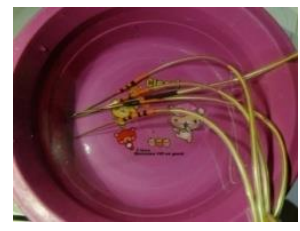

(a)

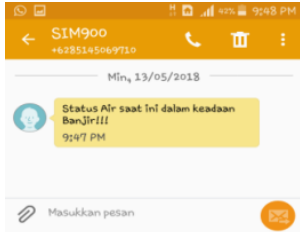

(b)

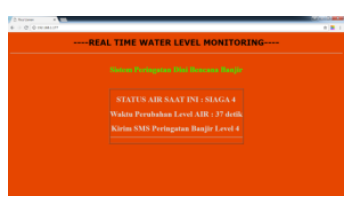

(c)

Gambar 11 (a) Sensor level 4 dihubungkan dengan air (b) Notifikasi SMS saat air level 4 (c) Tampilan web browser saat level 4

Tabel Hasil Pengujian Alat: Dari data hasil pengujian rangkaian keseluruhan alat dapat dilihat pada tabel 1

\begin{tabular}{|c|c|c|c|c|c|c|c|c|c|c|}
\hline \multicolumn{4}{|c|}{ INPUT } & \multicolumn{7}{|c|}{ OUTPUT } \\
\hline Sensor 1 & Sensor 2 & Sensor 3 & Sensor 4 & LCD & & LEI & & & SMS & WEB SERVER \\
\hline 0 & 0 & 0 & 0 & Siatus nommal & \begin{tabular}{|l|l|}
1 \\
Off
\end{tabular} & \begin{tabular}{l|l|l|}
2 & \\
Off & \\
\end{tabular} & & \begin{tabular}{l|l}
4 \\
$f f$
\end{tabular} & $x$ & Ketingrian air Normal \\
\hline 1 & 0 & 0 & 0 & Status Siaga & on & off & fff & fff & $\begin{array}{c}\text { Status sigag } \\
\text { Level air SSiga a }\end{array}$ & Ketinggian Air Siaga 1 \\
\hline 1 & 1 & 0 & 0 & Status waspada & On & On & $\mathrm{fff} \mid$ & fff & $\begin{array}{l}\text { Status waspada } \\
\text { Level air Siaga } 2\end{array}$ & Ketinggian Air Siaga 2 \\
\hline 1 & 1 & 1 & 0 & Status Bahaya & On & on & $\mathrm{on}$ & fff & $\begin{array}{l}\text { Status Bahaya } \\
\text { Level air Siaga } 3\end{array}$ & Ketinggian Air Siaga 3 \\
\hline 1 & 1 & 1 & 1 & Status Banjir!!! & $\mathrm{On}_{\mathrm{n}}$ & on & on & on & $\begin{array}{c}\text { Status Air siaga } 4 \\
\text { sungai dalam } \\
\text { keadanan Banii }\end{array}$ & Ketinggian Air Sia \\
\hline
\end{tabular}


Tabel 1 hasil pengujian alat

Ket:

- $0=$ Sensor tidak dihubungkan air

- $1=$ Sensor dihubungkan dengan air

- $\quad \mathrm{x}=$ Tidak ada notifikasi SMS

\section{KESIMPULAN}

Hasil perancangan sistem peringatan dini bencana banjir berbasis miokrokontroler Arduino telah berhasil dirancang dan diimplementasikan dalam bentuk prototype,sesuai dengan hasil uji prototype, maka sistem dapat memberikan status peringatan banjir melalui web browser dan SMSgateway.

\section{SARAN}

Dalam penelitian yang telah dilakukan ini, terdapat beberapa saran yang kiranya dapat bermanfaat yaitu:

1. Karena sistem peringatan bencana banjir ini hanya terintgrasi dengan web server lokal, maka dapat dikembangkan dengan melakukan integrasi dengan internet, sehingga web server dapat diakses oleh seluruh pengguna internet.

2. Sistem ini dapat dikembangkan dengan menambahkan SMSmasking yaitu SMS yang berupa nama bukan nomor handphone seperti SMS pada umumnya.

3. Belum adanya perangkat atau sistem backup listrik mengingat adanya kemungkinan terjadinya gangguan listrik sehingga dapat menyebabkan sistem tidak dapat beroperasi.

\section{DAFTAR PUSTAKA}

[1] Afrina, Mira.Dkk. 2015, Pengembangan Sistem Informasi SMSGateway Dalam Meningkatkan Layanan Komunikasi Sekitar Akademika Universitas Sriwijaya.

[2] Aryanto, Dkk. 2015, Perancangan Sistem Peringatan Dini Bencana Banjir Berbasis
Mikrokontroler Atmega328 Dan SMS Gateway Pada Kecamatan Rumbai Pesisir Pekan Baru.

[3] Dinata marta yuwono, 2016 Arduino itu Pintar. Penerbit PT. elex media komputindo, jakarta

[4] Gunarta, Lilik. 2011. Mengenal Sensor Dan Actuator. Universitas Airlangga.

[5] Kadir, abdul, 2012 panduan praktis mempelajari aplikasi mikrokontroler dan pemogramannya menggunakan Arduino. Penerbit andi.

[6] Kadir abdul, 2017 pemograman Arduino dan processing. Penerbit PT. Elex media komputindo.

[7] Mulyana, I Eka, Dkk. 2014. Perancangan Alat Peringatan Dini Bahaya Banjir Dengan Mikrokontroler Arduino Uno R3. Stimik Tasikmalaya.

[8] Mulyani Isnawati, dkk. 2013 Pengembangan Short Message Service (SMS) gateway layanan informasi akademik di smk yppt garut

[9] Rosydie, Arif. 2013. Fakta Dan Dampaknya, Serta Pengaruh Dari Perubahan Guna Lahan.

[10] Ryandi, Haris, Inmas. 2017. Rancang Bangun Sistem Meluapnya Air Sungai Melalui SMS Dan Running Text. Institut Teknologi Sepuluh November.

[11] Schifo, Frans. Dkk. Monitoring Level Air Dan Peringatan Dini Bahaya Banjir Berbasis SMS. Universitas Diponegoro.

[12] Simanjuntak, Maratur, Gabe. Dkk, 2013. Perancangan Prototipe Smart Building Berbasis Arduino Uno. Universitas Sumatra Utara.

[13]Ubnt.datasheet.www.ubnt.com/airmax\#airMax Antennashttps://dl.ubnt.com/datasheets/

[14] Utami, Ema. Dkk. 2008. Sistem Peringatan Dini Pada Bencana Banjir Berbasis SMS Gateway Di Gnu/Linux Merupakan Alternatif Sederhana Dan Menarik Dalam Meningkatkan Pelayanan Badan Meteorologi Dan Geofisika Dengan Alokasi Dana Yang Rendah. 